\title{
The art of predicting fibrosis in hepatitis $\mathrm{C}$
}

Infection with hepatitis $\mathrm{C}$ virus (HCV) is the most common cause of chronic hepatitis in our setting. The magnitude of the health and social problem posed by this infection is enormous, as it entails a reduction of life expectancy in these patients, and results in high social and financial costs when progressing to advanced disease stages. Current therapy in relation to chronic hepatits $\mathrm{C}(\mathrm{CHC})$ is based on a combination of pegylated interferon alpha (PEG-IFN) and ribavirin (RBV) for a period of 12 months in patients with a 1 or 4 genotype, or for 6 months in subjects infected by genotype 2 or 3 . Using this therapy regimen a sustained virologic response is seen in $45-55 \%$ of patients with genotype 1 , in nearly $65-70 \%$ of subjects with genotype 4 , and in $75-90 \%$ of patients with genotype 2 or 3 (1-3). This noticeable improvement in antiviral therapy efficacy does not exclude that a knowledge of fibrosis stage is still surely valuable to establish a prognosis and the need for antiviral therapy.

Liver biopsy is still the gold standard for liver fibrosis staging. In order to reduce intra- and inter-observer variability, numerous liver damage (including of course fibrosis) quantitation systems have been developed, including Knodell index (4), a modification thereof by Ishak et al. (5), and the METAVIR score (6). Despite the valuable teachings of liver biopsy in the field of Hepatology, and despite its unquestionable diagnostic capability, this technique has a number of limitations, including: a) a relatively high probability of sampling error (may preclude a cirrhosis diagnosis in up to $15-20 \%$ of cases); b) a relatively small sample size reducing the technique's sensitivity in the diagnosis of advanced fibrosis; in fact, fibrosis is usually underestimated in small-size samples; c) non-negligible morbidity and mortality, and poor patient acceptance, especially if a second test is required; d) a high economic cost, as it requires admission for a few hours; and e) and a snapshot when fibrosis is a clearly dynamic process.

An ideal diagnostic technique to quantitate liver fibrosis should be user-friendly, inexpensive, safe, free of side effects, specific, sensitive, reproducible, independent of metabolic changes, easy to perform, non-influencible by biliary or urinary clearance, and fit to reflect fibrosis regardless of cause. With this goal in mind, various fibrosis models have been developed in recent years based on relatively simple serologic measurements, which have proven useful to assess liver fibrosis extent in patients with chronic hepatitis $\mathrm{C}$, even though they obviously do not meet all the aforementioned characteristics. These fibrosis-predicting models may be clustered in 3 types: a) models using indirect markers for liver fibrosis; b) models using direct markers for liver fibrosis; and c) models combining indirect markers with insulinresistance tests.

In this issue Romera et al. (7) validate the prognostic Sydney fibrosis score in patients with hepatitis $\mathrm{C}$, and note that including insulin resistance in the predic- 
tion of advanced fibrosis or the exclusion of significant fibrosis slightly improves the APRI and Forns' scores. That is, it externally validates a score assessing insulin resistance as a fibrosis predictor (Sydney index), and then compares it to two previously-validated indirect liver fibrosis scores (Forns' and APRI) (8). The first test to identify the presence of significant fibrosis was maybe a GOT/GPT ratio $>1$, which has an $89 \%$ positive predictive value for cirrhosis (in the absence of alcohol use), but lacks utility to predict mild liver fibrosis. One of the first mathematical models to predict liver fibrosis extent according to indirect biochemical markers ( $\alpha 2$-macroglobulin, $\alpha 2$-globulin, haptoglobin, apolipoprotein- $A_{1}, \delta$-glutamyl transpeptidase, and total bilirubin) was developed by Imbert-Bismut et al. -the so-called Fibrotest (9). This test has a high negative predictive value regarding fibrosis for indices below 0.1 , and an acceptable positive predictive value regarding significant fibrosis (MATEVIR 2 or superior) for indices of 0.6-1. However, the need for payment regarding its calculation, and the use of markers usually not employed in daily practice obviously reduce practical utility. In order to solve both concerns, year 2003 sees the publication of the APRI index (GOT and platelets) (10), and shortly afterwards that of Forns' score (age, GGT, cholesterol, platelets, and prothrombin) (11), which share the use of variables commonly used in clinical practice in the development of their predictive models. Both tests have been validated in numerous patient groups, and satisfactorily compared to Fibrotest, even if the latter has a slightly better area under the ROC curve with a higher negative predictive value (12). The remaining two tests, despite a slightly lower area under the ROC curve and slightly lower accuracy, offer the benefit of simplicity for use, particularly the APRI test. Besides their usefulness for fibrosis prediction, some models, such as the one by Forns in combination with PCR-detected viremia, allow an estimation of response probability to antiviral therapy (13).

In patients with HCV-related chronic hepatitis the existence of overt insulin resistance has been consistently demonstrated, probably because of the virus' direct effect on intracellular insulin signalling (14). In fact, a clear correlation between fibrosis stage and HOMA (Homeostasis Model Assessment) index has been noted. In addition, the likeliness of response to antiviral therapy is lower in patients with greater insulin resistance, as has also been recently demonstrated by Dr. Romero's team (15). For this reason, Sud et al. developed a fibrosis predictive model (Sydney index) that also included fibrosis indirect markers, insulin resistance as assessed by HOMA (age, GOT, cholesterol, HOMA, and alcohol use) (16).

Other methods for fibrosis prediction are based on an estimation of parameters directly related to liver fibrosis, either alone or in combination. Probably, the individual test with the highest predictive value is hyaluronic acid determination (17). In addition, markers reflecting extracellular matrix deposition (including type-I procollagen C-terminal peptide, type-II procollagen N-terminal peptide, tissue inhibitor of metalloproteinase, and transforming growth factor beta), extracellular matrix breakdown (type-IV procollagen $\mathrm{C}$-terminal peptide, type-IV procollagen $\mathrm{N}$-terminal peptide, collagen IV, metalloproteinases), or a combination of a number of fibrosis direct markers, such as European Liver Fibrosis (18) (collagen propeptide III, TIMP-1, and hyaluronic acid), Fibrospect (19) ( $\alpha 2$-macroglobulin, TIMP-1, and hyaluronic acid), or SHASTA (20) (GOT, albumin, and hyaluronic acid). However, none of these direct markers of liver fibrosis, much less the combination of a number of them, is used in daily practice, which makes standardization, validation in extensive patient cohorts, and routine bedside use difficult. 
However, such notable advances in fibrosis prediction, both with methods directly assessing liver fibrosis and tests indirectly identifying liver fibrosis, are not exempt of relevant limitations. First, the absence of linearity in liver fibrosis makes a direct correlation between fibrosis score and stage difficult to establish. Secondly, these models are highly valuable in patients with extreme fibrosis (early or advanced stages); however, there is a wide subgroup of patients with intermediate fibrosis (F1, F2) where these predictive tests are of little help. Thirdly, the negative predictive value for significant fibrosis is usually inferior to that reported by authors in their validation series; anyway, it often deviates from quality standards (NPV $>85 \%$ ). Regarding site, some of the parameters used are rarely analyzed in daily practice. Last, these models have been exclusively validated in cross-sectional clinical trials, but their utility in longitudinal follow-up studies has not been systematically studied (there is some experience in hepatitis B though) (21). As may be seen in the paper by Romero et al., the major problems posed by non-invasive methods for fibrosis prediction in hepatitis $\mathrm{C}$ cannot be solved by including insulin resistance in the model, despite their close association with fibrosis progression.

To improve fibrosis prediction, and as a result of the limitations inherent to the above-mentioned markers, a number of approaches exist: a) the use of imaging techniques; b) the development of new technologies; and c) a combination of several indices. The development of new ultrasonographic techniques $(22,23)$ has allowed some authors to obtain positive predictive values for cirrhosis ranging from 82 to $88 \%$; however, high inter-observer variability is a major limitation. Computerized digital analysis of histologic preparations (24), or computerized analysis of CTcaptured images may reach a high value in the prediction of advanced fibrosis (25). However, the most useful technique in years to come will most likely be transient elastography $(26,27)$. Using a detector designated Fibroscan (Echosens, Paris, France), which includes an ultrasound transducer and produces a low-frequency, low-amplitude vibration, a friction wave is transmitted throughout a tissue. Tissue rigidity, fibrosis stage, and wave propagation rate are directly proportional. Initial studies in patients with hepatitis $\mathrm{C}$ demonstrated ROC-curve values for F1 to F4 stages of $0.90,0.88,0.91$, and 0.99 , respectively (28). Perhaps the most significant limitating factor in this technique is the assessment of obese patients, as fatty tissue severely attenuates both the friction wave and ultrasounds. Last, a reasonable approach is the combination of several indices or models. In fact, the concurrent use of APRI and Forns' scores has been seen to improve negative predictive value for fibrosis in genotype-1 patients. Similarly, the concurrent use of Fibroscan and Fibrotest has been recently seen to improve predictive capacity regarding fibrosis (29).

In the last few years, the numerous advances in serologic, virologic, and imaging diagnostic techniques have allowed an etiologic diagnosis in a high number of chronic liver conditions with no need for liver biopsy. Similarly, advances in the prediction of liver fibrosis have been worth of note, but have not reached clinical practice. A combination of two fibrosis prediction models using easy-to-access parameters (e.g., APRO index, Forns' score) and transient elastography will probably allow to satisfactorily define fibrosis extent in more than $75 \%$ of patients analyzed (except for genotype 3), particularly those with extremely low or high fibrosis. In such cases liver biopsy may likely be obviated, particularly in cases with an excellent response profile to antiviral therapy (genotypes 2 and 3). Regarding patients in the gray zone for prediction, we should wonder what do we expect from biopsy before biopsy performance. Only in cases where liver biopsy may change our diagno- 
sis (HCV-associated conditions) or -increasingly rarely- our therapy decision should we indicate it. In the near future a combination of fibrosis scores and imaging modalities may likely be precisely defined, which will allow us to predict both disease progression and prescribed therapy efficacy (in terms of fibrosis decrease).

\section{J. Crespo}

\section{Service of Digestive Diseases. Hospital Universitario Marqués de Valdecilla.} Santander, Spain

\section{References}

1. Manns MP, McHutchison JG, Gordon SC, Rustgi VK, Shiffman M, Reindollar R, et al. Peginterferon alfa-2b plus ribavirin compared with interferon $\alpha-2 b$ plus ribavirin for initial treatment of chronic hepatitis $C$ : a randomized trial. Lancet 2001; 358: 958-65.

2. Fried MW, Shiffman ML, Reddy R, Smith C, Marinos G, Gonçales FL, et al. Peginterferon $\alpha$-2a plus ribavirin for chronic hepatitis C virus infection. N Engl J Med 2002; 347: 975-82.

3. Hadziyannis SJ, Sette H, Jr., Morgan TR, Balan V, Diago M, Marcellin P, et al. Peginterferon- $\alpha-2 a$ and ribavirin combination therapy in chronic hepatitis $\mathrm{C}$ : a randomized study of treatment duration and ribavirin dose. Ann Intern Med 2004; 140: 346-55.

4. Knodell RG, Ishak KG, Black WC, Chen TS, Craig R, Kaplowitz N, et al. Formulation and application of a numeral scoring system for assessing histological activity in asymptomatic chronic active hepatitis. Hepatology 1981; 1: 431-5.

5. Ishak K, Baptista A, Bianchi L, Callea F, De Groote J, Gudat F, et al. Histological grading and staging of chronic hepatitis. J Hepatol 1995; 22: 696-9.

6. Bedossa P, Poynard T, for the French METAVIR cooperative study Group. An algoritm for grading activity in chronic hepatitis C. Hepatology 1996; 24: 289-93.

7. Romera M, Corpas R, Romero-Gómez M. La resistencia a la insulina en la valoración no invasiva de la fibrosis en pacientes con hepatitis C. Estudio comparativo de métodos bioquímicos. Rev Esp Enferm Dig 2006; 98: 161-9.

8. Romero M, Ramírez M, Otero MA, Vallejo M, Corpas R, Castellano-Megías VM. Estudio comparativo de 2 modelos que utilizan parámetros bioquímicos en el diagnóstico no invasivo de la fibrosis hepática en pacientes con hepatitis C. Med Clin (Barc) 2005; 124: 761-4.

9. Imbert-Bismut F, Ratziu V, Pieroni L, Charlotte F, Benhamou Y, Poynard T. Biochemical markers of liver fibrosis in patients with hepatitis $C$ virus infection: a prospective study. Lancet 2001; 357: 1069-75.

10. Wai CT, Greenson JK, Fontana RJ, Kalfleisch JD, Martero JA, Conjeevaram HS, et al. A simple non-invasive index can predict both significant fibrosis and cirrhosis in patients with chronic hepatitis C. Hepatology 2003; 38: 518-26.

11. Forns X, Ampurdanés S, LIovet JM, Aponte J, Quinto L, Martínez-Bauer E, et al. Identification of chronic hepatitis $C$ patients without hepatic fibrosis by a simple predictive model. Hepatology 2002; 36: 986-92.

12. Calvez S, Thabut D, Messous D, Munteanu M, Ratziu V, Imbert-Bismut F, et al. The predictive value of Fibro Test vs APRI for the diagnosis of fibrosis in chronic hepatitis C. Hepatology 2004; 39: 862-3.

13. Martínez-Bauer E, Crespo J, Romero-Gómez M, Moreno-Otero R, Solá R, Teser N, et al. Development and validation of simple scoring models for early prediction of response to antiviral therapy in genotype 1 chronic hepatitis C. Hepatology 2006; 43: 72-80.

14. Kawaguchi T, Yoshida T, Harada M, et al. Hepatitis C virus down-regulates insulin receptor substrates 1 and 2 through up-regulation of suppressor of cytokine signaling 3. Am J Pathol 2004; 165: 1499-508.

15. Romero-Gómez M, Del Mar Viloria M, Andrade RJ, Salmerón J, Diago M, Fernández-Rodríguez CM, et al. Insulin resistance impairs sustained response rate to peginterferon plus ribavirin in chronic hepatitis $\mathrm{C}$ patients. Gastroenterology. 2005; 128: 636-41.

16. Sud A, Hui JM, Farrell GC, Bandara P, Kench JG, Fung C, et al. Improved prediction of fibrosis in chronic hepatitis using measures of insulin resistance in a probability index. Hepatology 2004; 39: 1239-47.

17. Kelleher TB, Afdhal N. Assesment of fibrosis in clinical practice. In: Uptade in treatment of liver disease. In: Arroyo V, Navasa M, Forns X, Bataller R, Sánchez-Fueyo A, Rodés J, editors. Barcelona: Grupo Ars XXI de Comunicación; 2005. p. 463-74.

18. Rosenberg WM, Voelker M, Thiel R, Becka M, Burt A, Schuppan D, et al. for European Liver Fibrosis Group. Serum markers detect the presence of liver fibrosis: a cohort study. Gastroenterology 2004; 127: 170413.

19. Patel K, Gordon SC, Jacobson I, Hezode C, Oh E, Smith KM, et al. Evaluation of a panel of non-invasive serum markers to differentiate mild from moderate-to-advanced liver fibrosis in chronic hepatitis $\mathrm{C}$ patients. J Hepatol 2004; 41: 935-42.

20. Kelleher TB, Mehta SH, Bhaskar R, Sulkowski M, Astemborski J, Thomas DL, et al. Prediction of hepatic fibrosis in HIV/HCV co-infected patients using serum fibrosis markers: the SHASTA index. J Hepatol 2005; 43: 78-84.

21. Poynard T, Zoulim F, Ratziu V, Degos F, Imbert-Bismut F, Deny P, et al. Longitudinal assessment of histology surrogate markers (FibroTest-ActiTest) during lamivudine therapy in patients with chronic hepatitis B infection. Am J Gastroenterol 2005; 100: 1970-80. 
22. Schneider ARJ, Teuber G, Kriener S, Caspary WF. Noninvasive assessment of liver steatosis, fibrosis and inflammation in chronic hepatitis C virus infection. Liver International 2005: 25: 1150-5.

23. Yamada H, Ebara M, Yamaguchi T, Okabe S, Fukuda H, Yoshikawa M, et al. A pilot approach for quantitative assessment of liver fibrosis using ultrasound: preliminary results in 79 cases. J Hepatol 2006; 44: 68-75.

24. Lazzarini AL, Levine RA, Ploutz-Snyder RJ, Sanderson SO. Advances in digital quantification technique enhance discrimination between mild and advanced liver fibrosis in chronic hepatitis C. Liver Int 2005; 25: 1142-9.

25. Romero M, Gómez E, Vera M, Rodrigo L, Pérez R, Sola R, et al. Valoración de la fibrosis mediante análisis óptico de imágenes de TAC de hígado en hepatitis C: un método útil y no invasivo. Gastroenterol Hepatol 2005; 28 (Supl. 1): 49-119.

26. Ziol M, Handra-Luca A, Kettaneh A, Christidis C, Mal F, Kazemi F, et al. Noninvasive assessment of liver fibrosis by measurement of stiffness in patients with chronic hepatitis C. Hepatology 2005; 41: 48-54.

27. Foucher J, Chanteloup E, Vergniol J, Castera L, Le Bail B, Adhoute X, et al. Diagnosis of cirrhosis by transient elastography (Fibroscan(R)): a prospective study. Gut 2005

28. Sandrin L, Fourquet B, Hasquenoph JM, Yon S, Fournier C, Mal F, et al. Transient elastography: a new noninvasive method for assessment of hepatic fibrosis. Ultrasound Med Biol 2003; 29: 1705-13.

29. Castéra L, Vergniol J, Foucher J, Le Bail B, Chanteloup E, Haaser M, et al. Prospective comparison of Transient Elastography, Fibrotest, APRI, and Liver biopsy for the assessment of fibrosis in chronic hepatitis C. Gastroenterology 2005; 128: 343-50. 